\title{
Escorregamentos translacionais rasos no município de Camaragibe, região metropolitana do Recife: Uma análise preliminar a partir do modelo SHALSTAB
}

\author{
Shallow landslides in the municipality of Camaragibe, metropolitan region of Recife: A \\ preliminary analysis from the SHALSTAB model
}

SANTOS ${ }^{1}$, E. M.; LISTO $^{2}$, F. L. R.

edwilsonm.santos@gmail.com

\begin{abstract}
Resumo
Os processos que envolvem movimentos de massa estão diretamente ligados ao uso inadequado do solo. O município de Camaragibe é um dos principais locais com ocorrência de escorregamentos no Estado de Pernambuco. Por conta do processo de ocupação na área é frequente a ocorrência de escorregamentos, principalmente nos períodos chuvosos. Este trabalho teve como objetivo analisar, preliminarmente, a aplicabilidade do modelo SHALSTAB para identificar áreas suscetíveis a escorregamentos rasos em um dos bairros do município, denominado bairro dos Estados. Assim, foi utilizado o modelo SHALSTAB para mapear áreas suscetíveis a escorregamentos por meio de dados obtidos na literatura. Posteriormente essas áreas foram sobrepostas com o inventario de cicatrizes para o bairro dos Estados. A área é, majoritariamente, composta por áreas urbanizadas (57\%). Foram identificadas 49 cicatrizes de escorregamentos. Segundo o mapa de suscetibilidade, não há áreas incondicionalmente instáveis e 97,36\% da área é considerada estável. Aproximadamente, $80 \%$ das cicatrizes estão localizadas em áreas consideradas estáveis, de acordo com o modelo. A partir dos resultados encontrados, verificou-se que as diversas intervenções antrópicas existentes no local em conjunto com a falta de infraestrutura básica são os principais fatores que causam instabilidade nas encostas do bairro dos Estados, mesmo naquelas pouco suscetíveis.
\end{abstract}

Palavras-chave: Escorregamentos; Camaragibe; SHALSTAB.

\begin{abstract}
The processes that involve mass movements are directly related to the inadequate use of the soil. The municipality of Camaragibe is one of the main places with occurrence of landslides in the State of Pernambuco. Because of the occupation process in the area, there is frequent occurrence of landslides, mainly in rainy periods. This work aimed to analyze, preliminarily, the applicability of the SHALSTAB model to identify areas susceptible to shallow landslides in one of the districts of the municipality, called Estados neighborhood. Thus, the SHALSTAB model was used to map areas susceptible to landslides by means of data obtained in the literature. Subsequently, these areas were superimposed with an inventory of scars for the neighborhood of Estados. The area is mostly composed of urbanized areas (57\%). It was identified 49 scars of landslides. According to the susceptibility map, there are no unconditionally unstable areas and $97.36 \%$ of the area is considered stable. Approximately $80 \%$ of the scars are located in areas considered stable, according to the SHALSTAB model. From the results found, it was verified that the diverse anthropic interventions existing in the place together with the lack of basic infrastructure are the main factors that cause instability in the slopes of the Estados neighborhood, even in those that are not very susceptible.
\end{abstract}

Keywords: Landslides; Camaragibe; SHALSTAB.

\section{INTRODUÇÃO}

Os processos que envolvem movimentos de massa são recorrentemente investigados por causa dos diversos eventos que ocorrem, frequentemente, em diversas áreas do Brasil. Muitos desses eventos são acelerados em função do modo com o qual o homem lida com a paisagem, 
sobretudo pela ocupação de locais naturalmente mais suscetíveis a escorregamentos (SELBY, 1993; AUGUSTO FILHO; VIRGÍlI, 1998; FERNANDES; AMARAL, 1998; GUIMARÃES et al., 2003). Aliado a isso soma-se o acelerado processo de urbanização verificado nas últimas décadas, tanto nacionalmente quanto internacionalmente, resultando no intenso crescimento das cidades e na ampliação de áreas consideradas de risco.

Apesar dos movimentos de massa terem suas origens com ou sem a intervenção antrópica, as modificações impostas pela ação do homem se constituem em fator acelerador e de ampla repercussão espacial de impactos sobre os sistemas ambientais, portanto, a ação antrópica vem se constituindo em um dos principais fatores modificadores e desencadeadores da quebra da estabilidade dinâmica das encostas (GIRÃO e CORRÊA, 2004).

Os escorregamentos, particularmente, são processos de movimentos de massa bastante comuns nas regiões Nordeste, Sul e Sudeste do Brasil, principalmente nos períodos de chuva intensa. Guidicini e Nieble (1984) caracterizam os escorregamentos como movimentos rápidos, de curta duração, com plano de ruptura bem definidos, de porções de terrenos, deslocando-se sob ação da gravidade, para baixo e para fora do talude ou da encosta. Segundo Guerra (2016), estes eventos podem ocorrer em diferentes paisagens, desde que haja um relevo local propício de gerar uma força gravitacional que possa transportar rocha e/ou solo. Conforme Lopes e Arruda Junior (2015), esses processos são os mais marcantes na evolução natural das encostas, seja pela frequência com que ocorrem, seja pelo potencial de causar danos ao homem.

Diante deste quadro, a adoção de medidas preventivas, estruturais e não estruturais, podem evitar ou minimizar os danos negativos causados pela ocorrência de escorregamentos.

Dentre as medidas não estruturais, o mapeamento de áreas susceptíveis a escorregamentos rasos pode ser considerado como um procedimento essencial aos órgãos de Defesa Civil das diversas esferas governamentais, pois, permite a criação de planos de prevenção e o gerenciamento deste tipo de desastre (NUNES et al., 2016). Contudo, essa previsão não é uma tarefa simples por conta da complexidade dos fatores que controlam a estabilidade das encostas. Por isso, foram desenvolvidos diferentes métodos/ferramentas que avaliam, sob diferentes escalas, o papel dos fatores condicionantes e deflagradores (VIEIRA e RAMOS, 2015). Diante disso, as geotecnologias se transformam em ferramentas importantes para a análise destes processos, com destaque para os mapeamentos direcionados para caracterização do meio físico, especialmente as metodologias que utilizam modelos matemáticos baseados em bases físicas.

Estes modelos buscam avaliar a suscetibilidade de uma determinada área por meio de ambientes de Sistema de Informações Geográficas (SIG), a partir de equações matemáticas que descrevem o comportamento dos processos que influenciam, entre outros eventos, os 
escorregamentos (CHRISTOFOLETTI, 1999). Listo (2016) confirma a importância do uso destes modelos para a previsão de áreas susceptíveis a escorregamentos translacionais rasos ao caracterizalos como uma ferramenta extremamente objetiva, simples e de baixo custo no auxílio à redução das situações negativas geradas pelos escorregamentos.

Dentre os diversos modelos matemáticos para a previsão dos graus de suscetibilidade das encostas, destacando-se os modelos SHALSTAB (Shallow Landslide Stability) (MONTGOMERY e DIETRICH, 1994); SINMAP (Stability Index Mapping) (PACK et al., 2010) e TRIGRS (Transient Rainfall Infiltration and Grid-based Regional) (BAUM, SAVAGE e GODT, 2002). Esses modelos possuem como base os modelos de estabilidade e hidrológicos, considerando informações físicas dos solos e hidrológicas das encostas.

A utilização do modelo SHALSTAB no presente estudo se justifica devido a sua utilização com sucesso em estudos semelhantes aplicados em diversas áreas no Brasil, como nos trabalhos de Fernandes et al. (2001) e Silva (2006), no Estado do Rio de Janeiro, Ramos et al. (2003) em Salvador (BA), Vieira e Ramos (2015) na Serra do Mar (SP) e Listo (2011) em uma área densamente ocupada no município de São Paulo (SP).

Como parte de um estudo maior que envolve a identificação de áreas susceptíveis a escorregamentos translacionais rasos em todo território do município de Camaragibe, Região Metropolitana do Recife, o presente trabalho tem como objetivo analisar, de forma preliminar, a aplicabilidade do modelo SHALSTAB para identificar áreas suscetíveis a escorregamentos translacionais rasos no bairro dos Estados, município de Camaragibe.

\section{METODOLOGIA}

\section{1 Área de Estudo}

O município de Camaragibe se destaca pelos frequentes registros de escorregamentos. Os problemas causados pelos escorregamentos são agravados pela forma inadequada da ocupação de suas encostas, onde a maioria dos imóveis apresenta baixo padrão construtivo. Acrescenta-se a isso a ausência de infraestrutura e intervenções inadequadas, como cortes e aterros, por parte da população.

O bairro dos Estados localiza-se na região sul do município (Figura 1) e possui uma área inferior a um quilômetro quadrado $\left(0,8 \mathrm{~km}^{2}\right)$. Sua ocupação ocorreu de modo semiformal progressiva, efetuada pela população de baixa renda sem o planejamento adequado, a partir de loteamentos de baixa renda aprovados pelo poder público, seguidos de autoconstrução (Figura 2) (BANDEIRA, 2003). 


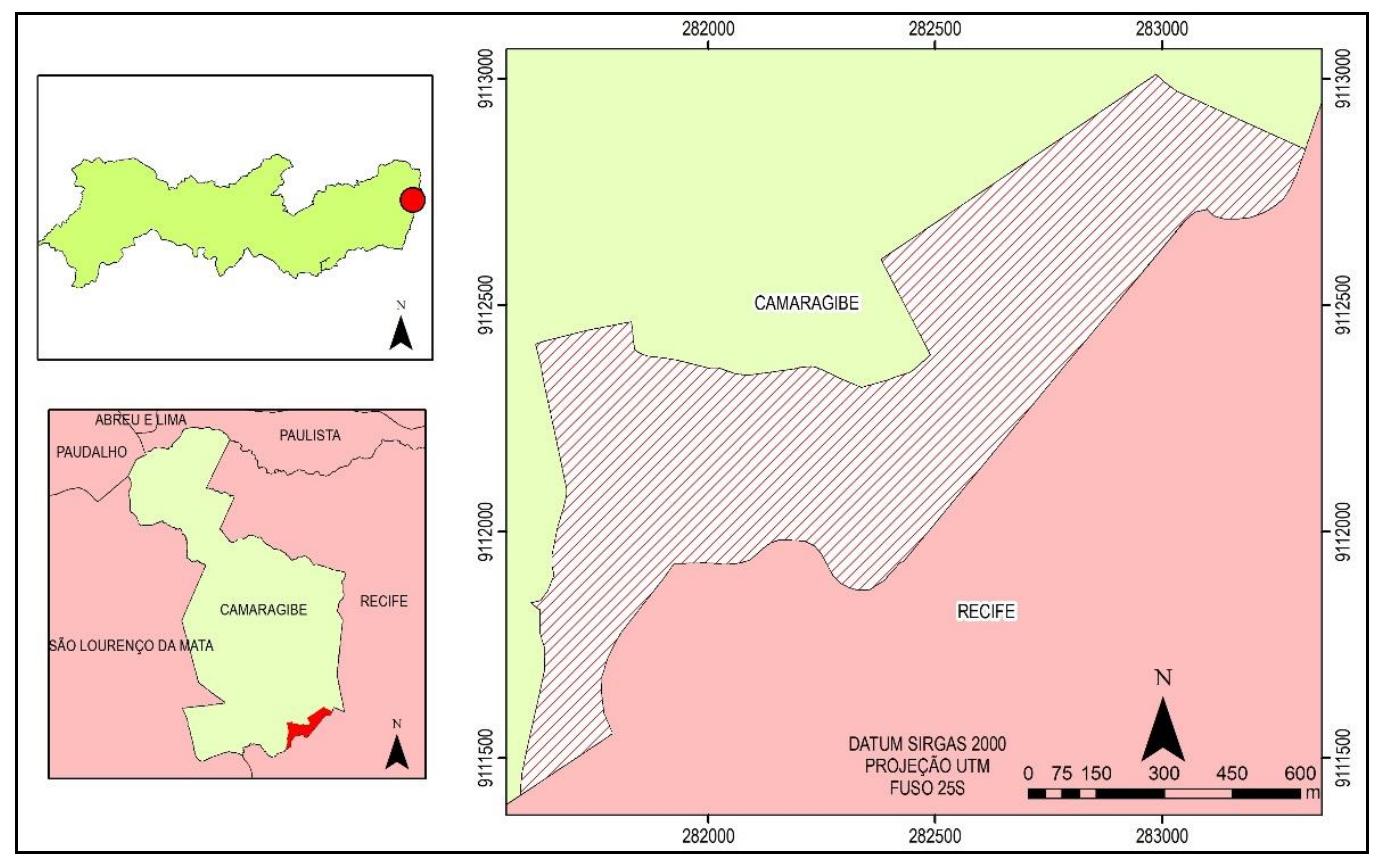

Figura 1. Localização da área de estudo. Fonte: autores (2018).

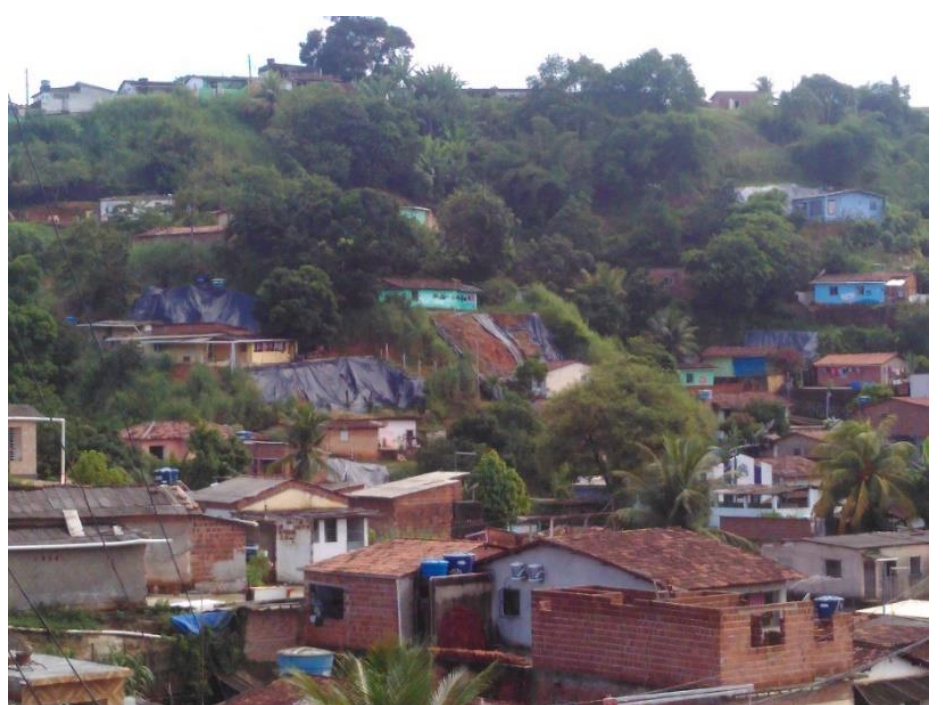

Figura 2. Ocupações em área de encosta no bairro dos Estados (abril/2018). Fonte: registrado pelos autores.

No referido bairro observam-se diversas encostas onde ocorreram cortes e aterros inadequados, retirada da cobertura vegetal, lançamento de águas servidas e construção de fossas nas bordas do talude, dentre outros fatores que contribuem para a instabilidade das encostas.

Assim como o município de Camaragibe, a área de estudo enquadra-se no clima do tipo As', pela classificação de W. Köppen, caracterizado como clima tropical chuvoso com verão seco e uma estação chuvosa, apresentando temperatura média anual de $25^{\circ} \mathrm{C}$ e pluviosidade anual de $1.710 \mathrm{~mm}$ (ALVARES et al., 2013). Essas características climáticas favorecem os processos de intemperismo químico, que decompõem os minerais mais frágeis, como o feldspato e as micas que são comuns 
nas rochas graníticas do embasamento cristalino e nas coberturas sedimentares, promovendo sua argilização, facilitando os processos de escorregamento, já que os grãos arenosos dos sedimentos da Formação Barreiras contribuem para aumentar o conteúdo de argila (BANDEIRA, 2003; ALHEIROS et al., 2004).

Segundo Bandeira (2003), em termos geomorfológicos, o município de Camaragibe apresenta três componentes bem definidos: Planície, Morros e Tabuleiros (Figura 3), que mostram uma planície fluviomarinha circundada por morros cristalinos e tabuleiros de rocha sedimentares. Segundo a Prefeitura de Camaragibe (2006), o município é constituído por cerca de $86 \%$ de áreas com relevos declivosos.

As áreas de morro são formadas pela evolução dos tabuleiros. Nas áreas mais dissecadas, ocorrem rochas do embasamento cristalino recobertas por solo residual. Os Tabuleiros são constituídos pelos sedimentos areno-argilosos da Formação Barreiras, onde é possível identificar fáceis deposicionais do tipo leque aluvial proximal, planície aluvial e canal fluvial (SILVA, SILVA e CORRÊA, 2008).

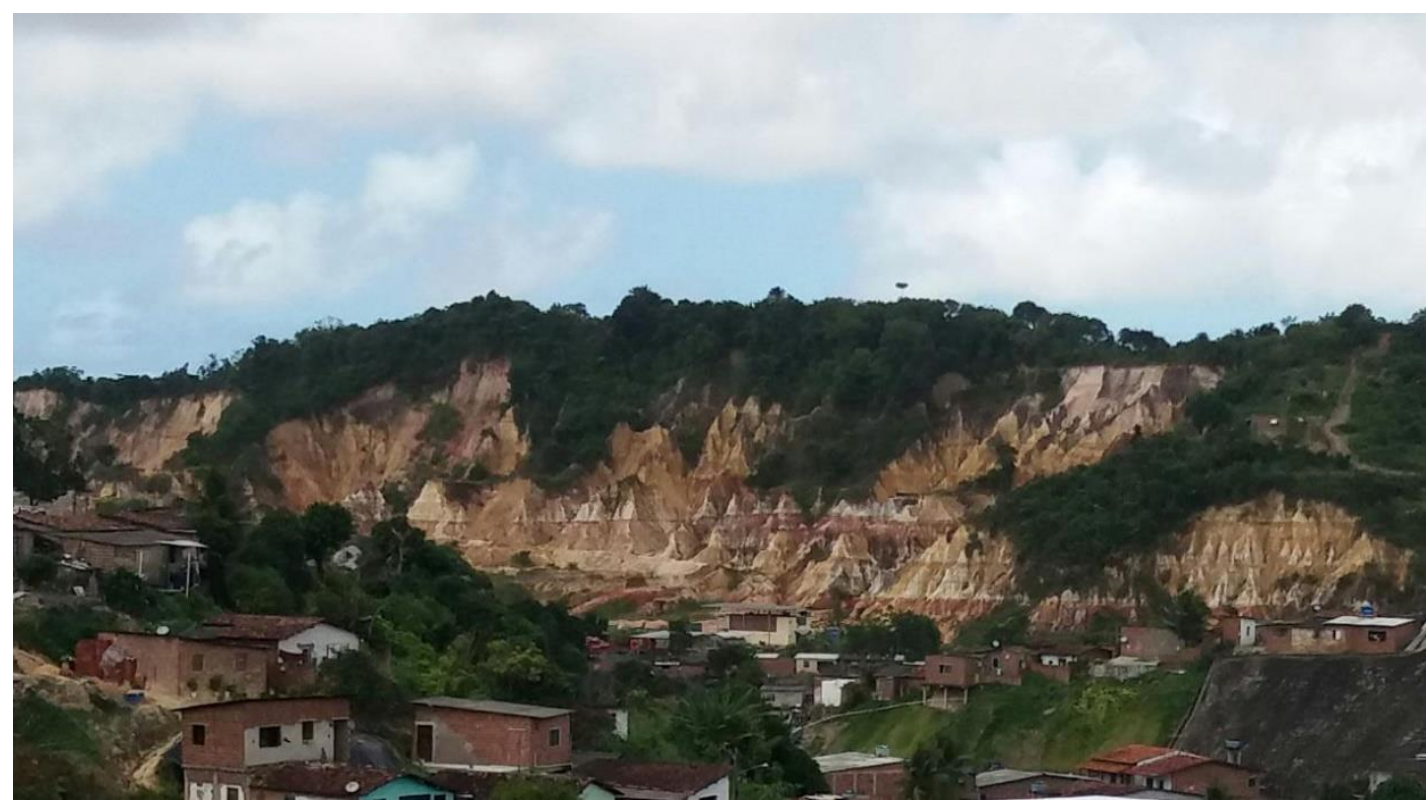

Figura 3. Tabuleiros dissecados no bairro dos Estados. Destaque para presença de processos erosivos. Fonte: registrado pelos autores

Nas áreas de morros predominam os Latossolos. Esta classe de solo se distribui sobre as unidades cristalinas e sobre o topo dos tabuleiros da Formação Barreiras, enquanto que os Argissolos ocupam, principalmente, as áreas mais elevadas que recobrem as unidades geológicas cristalinas e o terço médio dos sedimentos da Formação Barreiras (BANDEIRA, COUTINHO e ALHEIROS, 2005). 


\subsection{Modelo SHALSTAB}

O modelo SHALSTAB é definido como um modelo matemático determinístico que calcula a suscetibilidade a escorregamentos translacionais rasos, resultante da combinação de dois modelos, um de estabilidade de encostas, baseado no método do talude infinito (teoria do Fator de Segurança, desenvolvida por Mohr-Coulomb) e outro hidrológico (steady-state) desenvolvido por O’Loughlin (1986). Na combinação destes dois modelos, são incorporados respectivamente os parâmetros topográficos (declividade e área de contribuição), adquiridos a partir de um Modelo Digital de Terreno (MDT), e parâmetros físicos do solo ( $c s$ - coesão do solo $\left(\mathrm{N} / \mathrm{m}^{2}\right)$; $c r$ - coesão das raízes $\left(\mathrm{N} / \mathrm{m}^{2}\right) ; r s$ - peso específico do solo $\left(\mathrm{kg} / \mathrm{m}^{3}\right) ; f$ - ângulo de atrito (graus); $w$ - peso da vegetação $\left(\mathrm{N} / \mathrm{m}^{2}\right)$ e $z$ - profundidade de análise $\left.(\mathrm{m})\right)$, obtidos por meio de ensaios geotécnicos. A equação geral do modelo SHALSTAB, proposta por Montgomery e Dietrich (1994), é indicada na Equação 1.

$$
\log \left(\frac{Q}{T}\right)=\frac{\operatorname{sen} \theta}{\left(\frac{g}{b}\right)} \cdot\left[\frac{c^{r}}{\rho w \cdot g \cdot z \cdot \cos 2 \theta \cdot \tan \phi}+\frac{\rho s}{\rho w}\left(1-\frac{\tan \theta}{\tan \Phi}\right)\right]
$$

Onde: $a=$ área de contribuição $\left(\mathrm{m}^{2}\right) ; b=$ resolução do grid $(\mathrm{m}) ; C^{\prime}=$ coesão do solo $(\mathrm{kPa}) ; g$ $=$ aceleração da gravidade $\left(\mathrm{m} / \mathrm{s}^{2}\right) ; \theta=$ ângulo da encosta $\left(^{\circ}\right) ; P S=$ massa específica do solo saturado $\left(\mathrm{Kg} / \mathrm{m}^{3}\right) ; P w=$ densidade da água $\left(\mathrm{kg} / \mathrm{m}^{3}\right) ; Q=$ chuva em estado crítico necessária para a ruptura $\left(\mathrm{m} / \mathrm{dia}^{-1}\right) ; T=$ transmissividade do solo saturado $\left(\mathrm{m}^{2} \mathrm{dia}^{-1}\right) ; z=$ espessura do solo $(\mathrm{m}) ; \Phi=$ ângulo de atrito interno do solo $\left({ }^{\circ}\right)$.

Fernandes et al. (2001) explicam que o modelo SHALSTAB analisa, para cada célula dentro de um grid, obtido a partir de um MDT, o resultado da combinação de um módulo hidrológico, que modela os locais na paisagem que estarão submetidos a saturação, com um módulo de estabilidade, que simula a estabilidade de uma quantidade de solo situada diretamente sobre o embasamento rochoso. Como resultado final, o modelo gera sete classes de estabilidade, conforme o Quadro 1.

Quadro 1 - Classes de estabilidade do modelo SHALSTAB. Fonte: Montgomery e Dietrich (1998); Listo (2011).

\begin{tabular}{|l|l|}
\hline Classes originais do modelo $\log (\mathbf{q} / \mathbf{T})$ & \multicolumn{1}{c|}{ Classificação } \\
\hline Incondicionalmente estável & Incondicionalmente instável e saturado \\
\hline$<-3,1$ & Incondicionalmente instável e não saturado \\
\hline$-3,1--2,8$ & Instável e saturado \\
\hline$-2,8--2,5$ & Instável e não saturado \\
\hline$-2,5--2,2$ & Estável e não saturado \\
\hline$>-2,2$ & Incondicionalmente estável e não saturado \\
\hline Incondicionalmente Estável & Incondicionalmente estável e saturado \\
\hline
\end{tabular}

Os parâmetros físicos do solo utilizados para o mapeamento da suscetibilidade aos escorregamentos translacionais rasos na área de estudo foram obtidos na literatura, a partir do 
trabalho de Souza (2014), conforme apresentado na Tabela 1. Os parâmetros topográficos (declividade e área de contribuição) foram obtidos por meio de um MDT, com resolução espacial de 2,5m, disponibilizado pela CPRM (2014).

Tabela 1 - parâmetros físicos de solo. Fonte: Adaptado de Souza (2014)

\begin{tabular}{cc}
\hline PARÂMETRO & VALOR \\
\hline cs & $7.020 \mathrm{~N} / \mathrm{m}^{2}$ \\
cr & 0 \\
rs & $1.896 \mathrm{~kg} / \mathrm{m}^{3}$ \\
$\mathrm{f}$ & $35,32^{\circ}$ \\
$\mathrm{w}$ & 0 \\
$\mathrm{z}$ & $2 \mathrm{~m}$ \\
\hline
\end{tabular}

No ambiente SIG foi utilizada a ferramenta Automatic SHALSTAB Analysis (ASA), desenvolvida por Sbroglia et al. (2017). Essa ferramenta permite utilizar o modelo SHALSTAB diretamente no software ArcGIS, a partir de uma rotina automatizada inserida na caixa de ferramentas (ArcToolbox).

A identificação dos locais onde ocorreram escorregamentos foi realizado por meio de analise visual de imagens de satélite, datadas de setembro de 2017, disponíveis no software Google Earth, ocorrendo posterior validação in loco. A identificação destas áreas possibilitou a elaboração de um inventário de cicatrizes.

Por fim, foi realizada a sobreposição entre o mapa de suscetibilidade a escorregamentos translacionais rasos e o inventário de cicatrizes. Esse procedimento possibilitou calcular o índice de Concentração de Cicatrizes (CC), isto é, o número de células de cada classe de suscetibilidade afetadas pelas cicatrizes dos escorregamentos.

\section{RESULTADOS E DISCUSSÃO}

O bairro dos Estados é majoritariamente formado por áreas urbanizadas (57\%), compostas por imóveis residências e comerciais; áreas com vegetação rasteira $(19,5 \%)$, ou seja, áreas onde a vegetação se apresenta em estado de regeneração; áreas formadas por vegetação de porte arbóreo $(13,2 \%)$; e áreas de solo exposto (10,4\%). Observa-se que grande parte da área classificada como "solo exposto" se concentra em um local utilizado para exploração mineral, conforme destacado na Figura 4. 


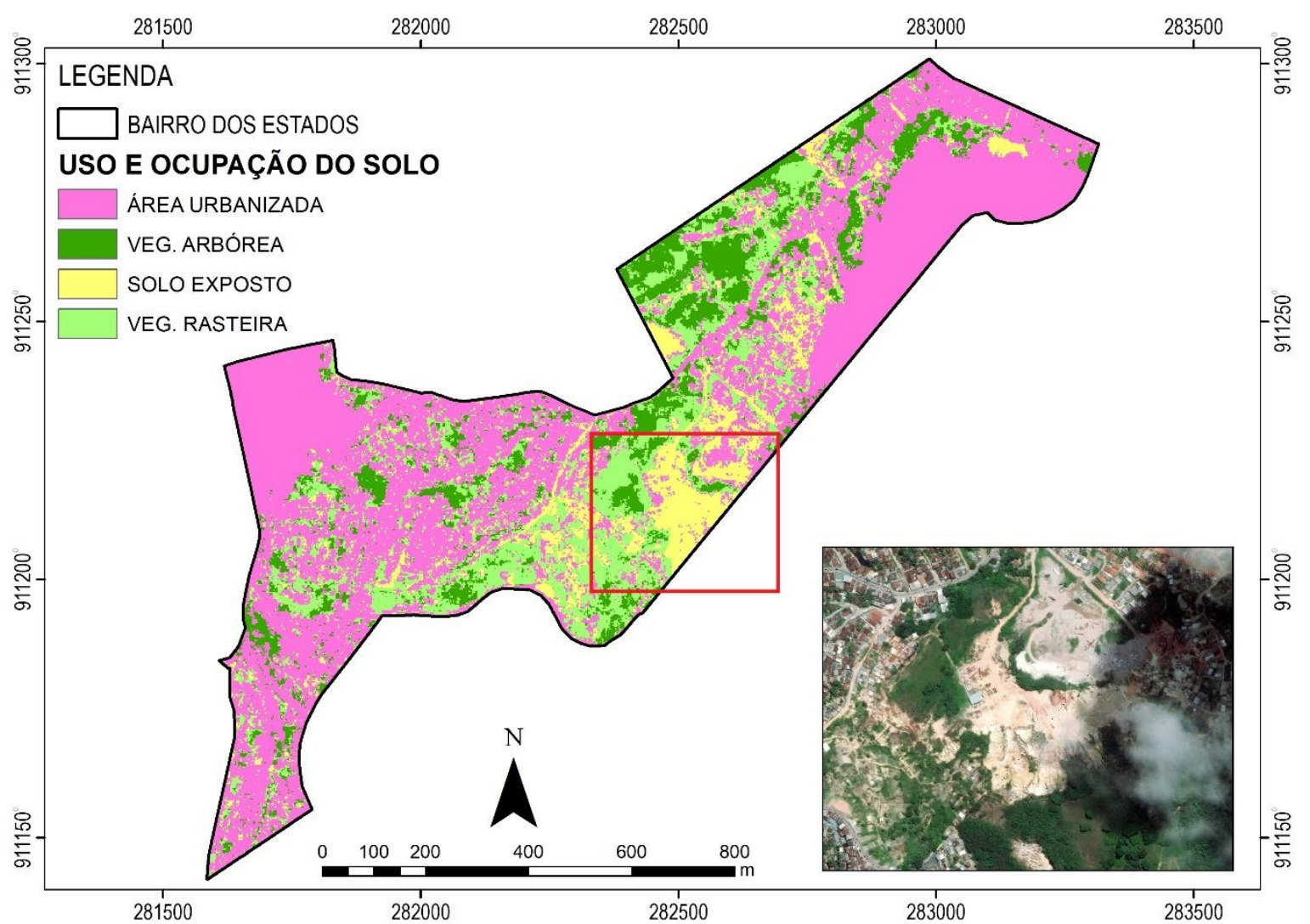

Figura 4 - Mapa de Uso e Ocupação da terra. Destaque para área com solos expostos. Fonte: elaborado pelos autores.

Ao todo foram identificadas 49 cicatrizes de escorregamentos. Essas cicatrizes se concentram nas áreas urbanizadas e nas localidades próximas destas áreas, conforme apresentado na Figura 5.

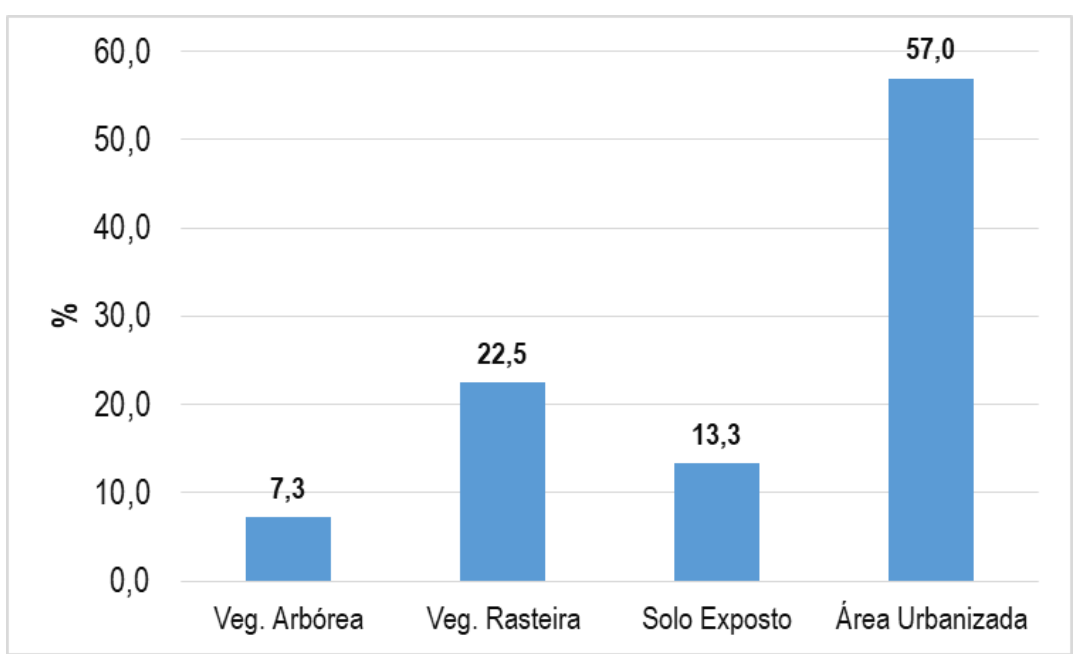

Figura 5 - Distribuição percentual das cicatrizes por tipo de uso do da terra. Fonte: elaborado pelos autores.

Segundo o mapa de declividade (Figura 6), o bairro dos Estados é formado, predominantemente, por áreas consideradas de baixa declividade (entre $0^{\circ}$ e $9,6^{\circ}$ ), ocupando 44,6\% 
da área total. Em seguida, com 30,9\%, a classe acima de $16,7^{\circ}$ e, finalmente, a classe entre 9,6 e $16,7^{\circ}$ com $24,5 \%$ da área. A partir da sobreposição entre o inventário de cicatrizes e o mapa de declividade, foi verificado que há uma CC de $80,7 \%$ na classe acima de $16,7^{\circ}$, notadamente mais íngreme e mais suscetível aos escorregamentos.

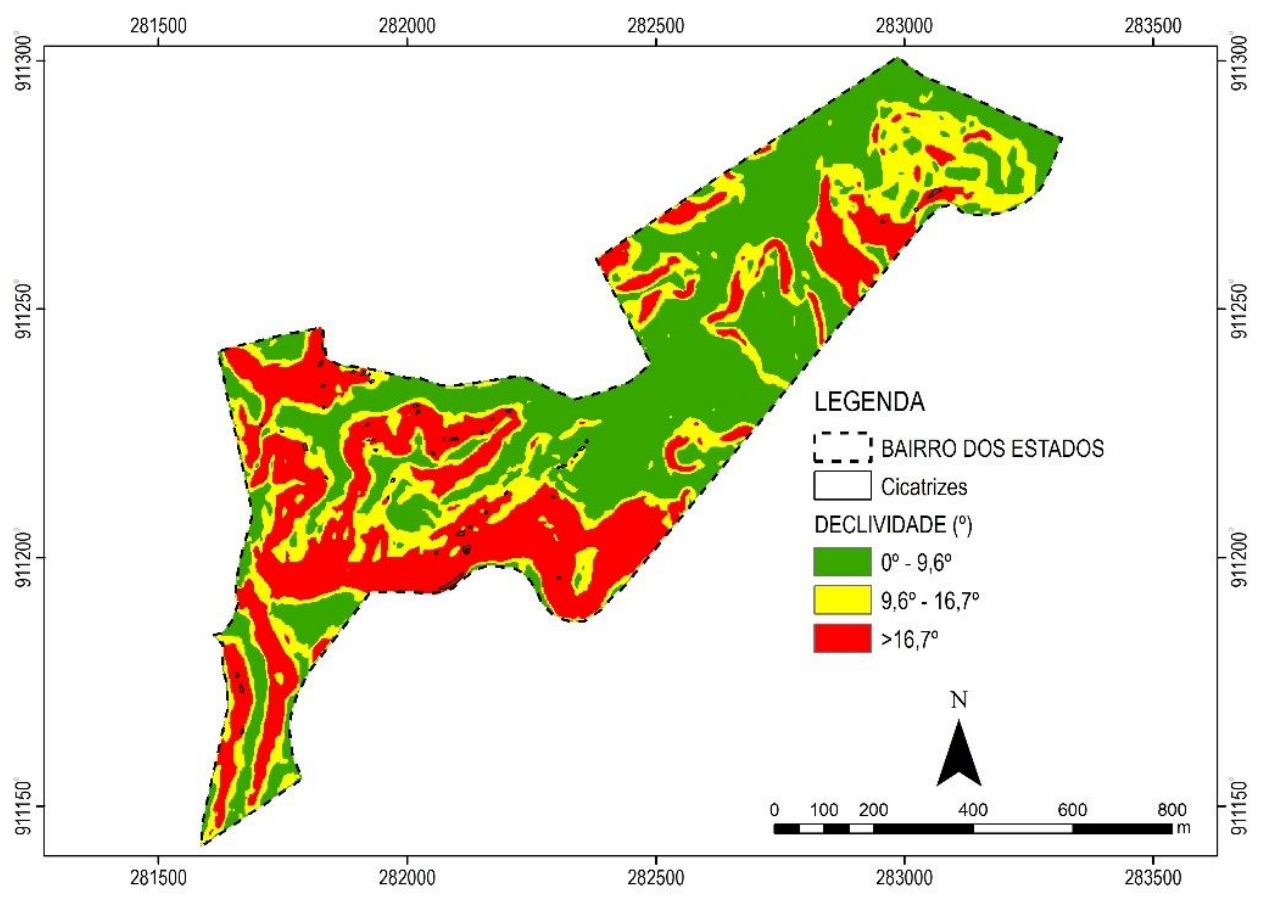

Figura 6 - Mapa de declividade. Fonte: elaborado pelos autores.

O mapa de suscetibilidade gerado pelo modelo SHALSTAB (Figura 7) apontou que o bairro dos Estados apresenta a maior parte de sua área classificada como estável (97,36\%). Também foi possível verificar que não há áreas classificadas como Incondicionalmente Instáveis, conforme detalhado na Figura 8. Quando sobreposto o mapa de suscetibilidade e o inventário de cicatrizes foi constatado que 79,7\% das cicatrizes se concentraram nas áreas consideradas estáveis (Estável e Log q/T >-2.2), enquanto que 20,3\% das cicatrizes se concentram nas áreas classificadas como instáveis $(-3,1--2,8 ;-2,8--2,5$ e $-2,5--2,2)$ (Figura 9). 


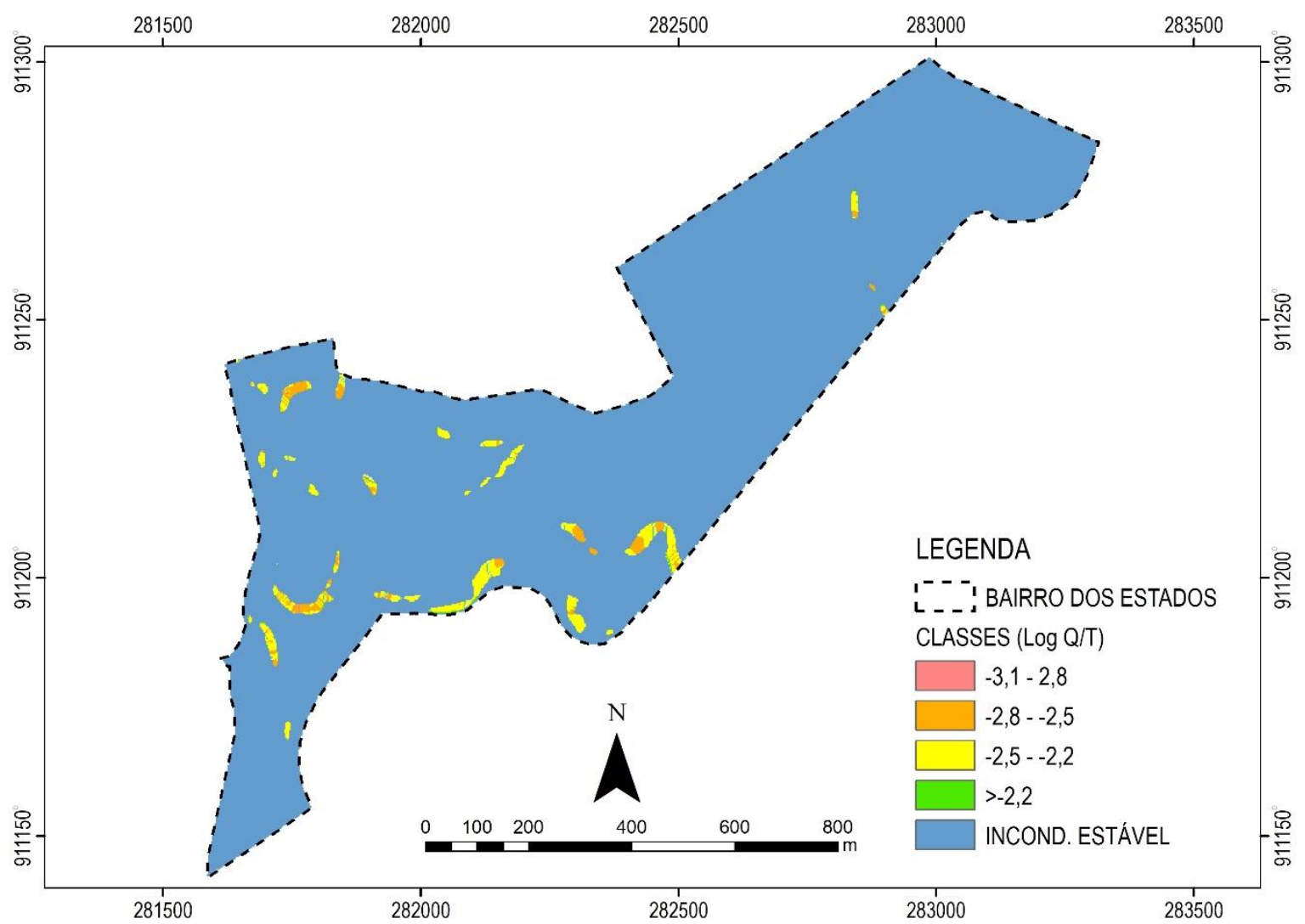

Figura 7 - Mapa de suscetibilidade a escorregamentos rasos gerado pelo modelo SHALSTAB. Parâmetros utilizados: $\mathrm{cs}=7.020 \mathrm{~N} / \mathrm{m}^{2} ; \mathrm{rs}=1.896 \mathrm{~kg} / \mathrm{m}^{3} ; \mathrm{f}=35,32^{\circ} ; \mathrm{z}=2 \mathrm{~m}$. Fonte: elaborado pelos autores (2018).

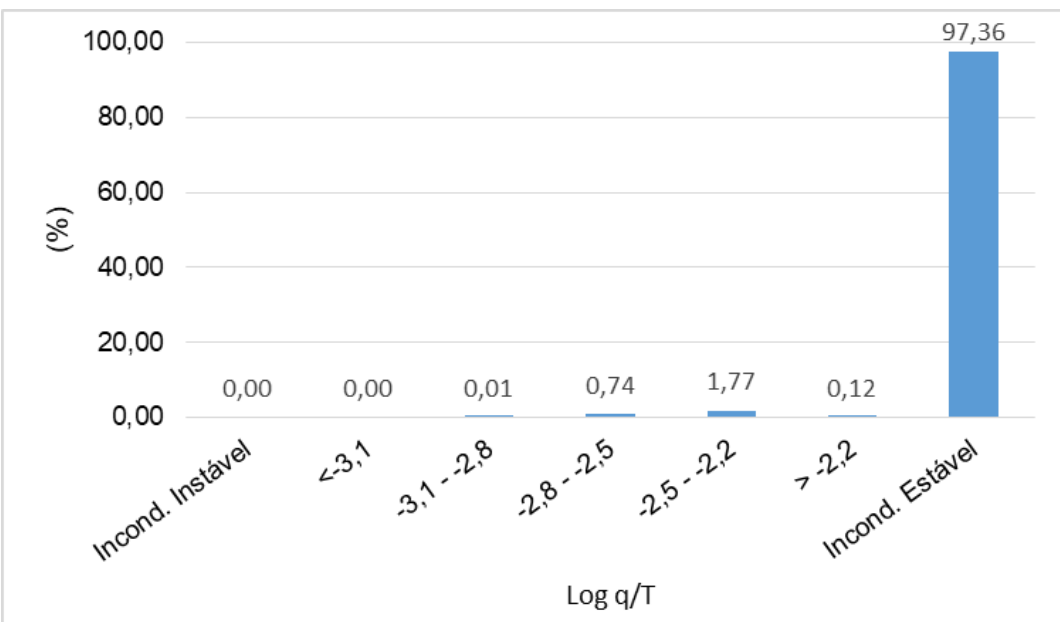

Figura 8 - Frequência das classes de suscetibilidade no bairro dos Estados. Fonte: elaborado pelos autores (2018). 


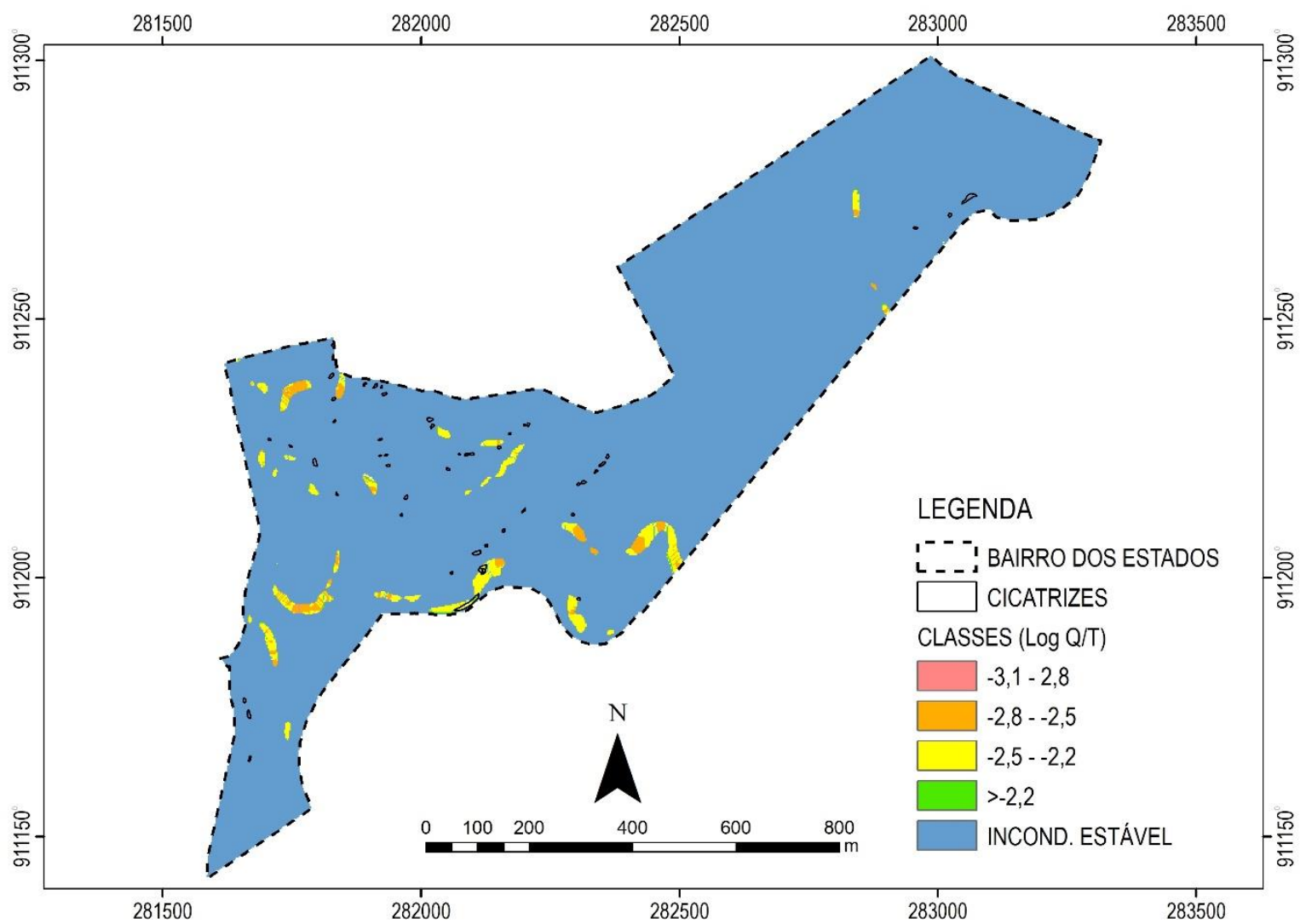

Figura 9 - Sobreposição entre o inventário de cicatrizes e o mapa de suscetibilidade. Fonte: elaborado pelos autores (2018).

A maior concentração de cicatrizes em áreas consideradas estáveis pelo modelo não necessariamente indica algum tipo de erro nos métodos aplicados. Conforme observado na Figura 5, a maior parcela das cicatrizes se concentra em áreas ocupadas ou em processo de ocupação. Diante deste cenário é possível afirmar que intervenções antrópicas potencializaram de modo significativo a estabilidade nas encostas que sofreram movimento de massa no bairro dos Estados. Observa-se que nestes locais, de maneira geral, ocorreram cortes na encosta juntamente com a retirada da cobertura vegetal para construção ou ampliação de imóveis e terrenos. A precária ou, em alguns casos, inexistência de infraestrutura básica, como abastecimento de água, coleta de lixo e esgoto, e rede de drenagem pode resultar na saturação do solo e posteriormente acarretar escorregamentos, conforme apresentado na Figura 10. 

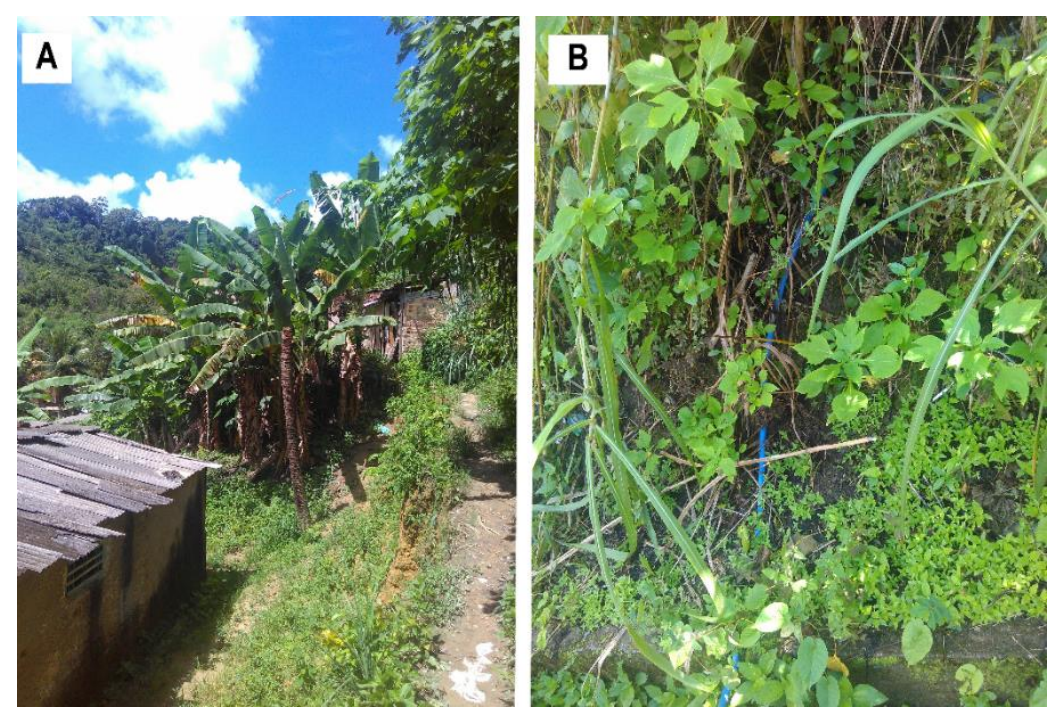

Figura 10 - Corte de parte da encosta (A) e ligações clandestinas da rede de abastecimento (B). Fonte: Autores (2018).

\section{CONSIDERAÇÕES FINAIS}

Diversos municípios brasileiros, dentre eles o município de Camaragibe, possuem áreas de risco a escorregamentos, principalmente, em função do modo como ocorreu a ocupação dessas áreas. É possível também incluir a ausência de infraestrutura básica nestes locais. Essas condições quando associadas a períodos chuvosos proporcionam o desiquilíbrio das encostas, sendo assim, é possível apontar que os processos que envolvem a ocupação e o uso da terra no bairro dos Estados favoreceram significativamente para a instabilidade de diversas encostas no local.

A influência antrópica como principal causa de instabilidade em algumas encostas do local é perfeitamente demonstrada por meio da concentração de cicatrizes de escorregamentos, majoritariamente, em áreas classificadas como estáveis, segundo os parâmetros físicos e topográficos. Assim, de acordo com os resultados do gerados pelo modelo SHALSTAB, ficou evidenciado que apesar existirem poucas áreas naturalmente suscetíveis aos escorregamentos, as práticas urbanas inadequadas proporcionaram condições que levaram a instabilidade de encostas poucos suscetíveis a escorregamentos.

Percebe-se que a maior parte das cicatrizes (70,3\%) estão distribuídas nas classes correspondente as áreas urbanizadas ou de solos expostos. Este número comprova a importância de estudos como este, no sentido de diagnosticar as atuais condições ambientais da área, servindo como uma ferramenta para orientação de ações voltadas a gestão do risco nessas áreas.

A aplicação do modelo SHALSTAB na análise da previsão de escorregamentos translacionais rasos já mostrou ser uma ferramenta relevante na prevenção de riscos de escorregamentos em diversos locais do Brasil, principalmente no Sul e Sudeste, sendo assim, destaca-se que sua utilização para áreas situadas no Nordeste brasileiro contribuirá na geração de 
subsídios para o entendimento dos mecanismos e dos fatores condicionantes desses fenômenos na região.

Quanto aos trabalhos futuros, serão levantadas as cicatrizes de escorregamentos nos demais bairros do município de Camaragibe, juntamente com o levantamento de mais dados envolvendo os parâmetros físicos do solo para mais aplicações do modelo SHALSTAB.

\section{REFERÊNCIAS}

ALHEIROS, M. M; SOUZA, M.A.A; BITOUN, J; MEDEIROS, S.M.G.M; AMORIM JÚNIOR, W.M. Manual de ocupação dos morros da região metropolitana do Recife. Recife: Ensol, 2004.

ALVARES, C. A.; STAPE, J. L.; SENTELHAS, P. C.; GONÇALVES, J. L. M.; SPAROVEK, G. Köppen's climate classification map for Brazil. Meteorologische Zeitschrift, Stuttgart, v. 22, n. 6, p. 711-728, 2013.

AUGUSTO FILHO, O.; VIRGÍLI, J. C. Estabilidade de taludes. In: OLIVEIRA, A. M. S.; BRITO, S. N. A. Geologia de Engenharia. São Paulo: ABGE-CNPq- FAPESP, 1998. p. 243-269.

BANDEIRA, A. P. N. Mapeamento de risco de erosão e escorregamento das encostas com ocupações desordenadas no município de Camaragibe - PE. Dissertação (mestrado) - Programa de Pós-Graduação em Engenharia Civil, Universidade Federal de Pernambuco. Recife, p. 209. 2003.

BANDEIRA, A. P.; COUTINHO, R. Q.; ALHEIROS, M. M. Importância da Caracterização Geológico-Geotécnica e da Chuva para Gerenciamento de Áreas de Riscos. Conferência Brasileira sobre Estabilidade de Encostas. Salvador: [s.n.]. 2005.

BAUM, R. L.; SAVAGE, W. Z.; GODT, J. W. TRIGRS: A FORTRAN Program for Transient Rainfall Infiltration and Grid-Based Regional Slope-Stability Analysis. Colorado: USGS, 2002.

CHRISTOFOLETTI, A. Modelagem de Sistemas Ambientais. São Paulo: Edgard Blücher, 1999.

CPRM. Cartas de Suscetibilidade a Movimentos Gravitacionais de Massa e Inundações Pernambuco. Serviço Geológico do Brasil. Brasília. 2014.

FERNANDES, N. F.; GUIMARÃES, R. F.; GOMES, R. A.T.; VIEIRA, B. C.; MONTGOMERY, D. R.; GREENBERG, H. Condicionantes Geomorfológicos dos Deslizamentos nas Encostas: Avaliação de Metodologias e Aplicação de Modelo de Previsão de Áreas Susceptíveis. Revista Brasileira de Geomorfologia, v. 2, n. 1, p. 51-71, 2001.

FERNANDES, N. F.; AMARAL, C. P. Movimentos de massa: Uma abordagem geológicogeomorfológica. In: GUERRA, A. J. T.; CUNHA, S. B. Geomorfologia e meio ambiente. 2a. ed. São Paulo: Bertrand, 1998. p. 123-194.

GIRÃO, O.; CORRÊA, A. C. B. A contribuição da geomorfologia para o planejamento da ocupação de novas áreas. Revista de Geografia. Recife, v. 21, n. 2, p.36-58, jul/dez. 2004. 
GUERRA, A. T. Erosão dos solos e movimentos de massa: abordagens geográficas. Curitiba: CRV, 2016.

GUIDICINI, G.; NIEBLE, C. M. Estabilidade de taludes naturais e de escavação. 2a. ed. São Paulo: Universidade de São Paulo, 1984.

GUIMARÃES, R. F.; FERnANDES, N. F.; GOMES, R. A. T.; CARVALHO JÚNIOR, O. A. Fundamentação teórica do modelo matemático para previsão de escorregamentos rasos Shallow Stability. Espaço \& Geografia, Brasilia, v. 6, n. 2, p. 133-150, 2003.

LISTO, F. L. R. Análise da suscetibilidade e do grau de risco a escorregamentos rasos na Bacia do Alto Aricanduva, RMSP (SP). Dissertação de mestrado. Departamento de Geografia, Universidade de São Paulo. São Paulo, p. 151. 2011.

. Modelos matemáticos aplicados à previsão de escorregamentos translacionais rasos: Exemplos em áreas naturais e de risco. Clio Arqueológica, Recife, v. 31, n. 3, p. 91-114, 2016.

LOPES, E. S. S.; ARRUDA JUNIOR, E. R. Sensoriamento Remoto para deslizamentos. In: SAUSEN, T. M.; LACRUZ, S. P. Sensoriamento Remoto para desastres. São Paulo: Oficina de textos, 2015. Cap. 8, p. 213-248.

MONTGOMERY, D. R.; DIETRICH, W. E. A physically based model for the topographic control on shallow landsliding. Water Resources Research, v. 30, p. 1153-1171, 1994.

NUNES, L. H. Urbanização e desastres naturais. São Paulo: Oficina de textos, 2015.

O'LOUGHLIN, E. M. Prediction of surface saturation zones in natural catchments by topographic analysis. Water Resources Research, n. 22, p. 794-804, 1986.

PACK, R. T.; TARBOTON, D.; GOODWIN, C. N.; PRASAD, A. SINMAP - a stability index approach to terrain stability hazard mapping. Utah: Utah State University, 2010.

PREFEITURA MUNICIPAL DE CAMARAGIBE. Plano municipal de redução de riscos em assentamentos precários do município de Camaragibe. Prefeitura municipal de Camaragibe. Camaragibe. 2006.

RAMOS, V. M.; GUIMARÃES, R. F.; REDIVO, A. L.; CARVAlHO JUNIOR, O. A. Mapeamento das áreas susceptíveis a escorregamentos rasos no subúrbio ferroviário de Salvador (BA), utilizando os parâmetros físicos diferenciados para cada classe de solo. Anais do X Simpósio brasileiro de geografia física aplicada, Juiz de Fora, 2003.

SBROGLIA, R. M.; PORATH, P. H. M.; HIGASHI, R. A. R.; OLIVEIRA, F. H. Mapeamento de Áreas Suscetíveis a Deslizamentos Translacionais com o Uso da Ferramenta ASA - Automatic Shalstab Analysis. Anais da XII Conferência Brasileira sobre Estabilidade de Encostas. Florianópolis, Santa Catarina, Brasil: [s.n.]. 2017.

SELBY, M. J. Hillslope materials and processes. 2a. ed. New York: Oxford University Press, 1993. 
SILVA, D. C. O. Aplicação do Modelo SHALSTAB na Previsão de Deslizamentos em Petrópolis - RJ. Dissertação de mestrado. Programa de Pós-Graduação de Engenharia, Universidade Federal do Rio de Janeiro. Rio de Janeiro, p. 148. 2006.

SILVA, D. N. F.; SILVA, I. C. G.; CORRÊA, A. C. B. Evolução morfodinâmica das encostas do Bairro dos Estados: Camaragibe - PE. Anais do VII Simpósio Nacional de Geomorfologia. Belo Horizonte: [s.n.]. 2008.

SOUZA, A. P. L. Estudos geotécnicos e de estabilidade de taludes da encosta do Alto do Padre Cícero no município de Camaragibe - PE. Dissertação (Mestrado). Programa de Pós-Graduação em Engenharia, Universidade Federal de Pernambuco. Recife, p. 177. 2014.

TOMINAGA, L. K. Escorregamentos. In: TOMINAGA, L. K.; SANTORO, J.; AMARAL, R. Desastres naturais: Conhecer para prevenir. São Paulo: Instituto Geológico, 2009. p. 27-38.

VIEIRA, B. C.; RAMOS, H. Aplicação do modelo SHALSTAB para mapeamento da Suscetibilidade a escorregamentos rasos em Caraguatatuba, Serra do Mar (SP). Revista do Departamento de Geografia - USP, São Paulo, v. 29, p. 161-174, 2015.

Recebido em: 07/08/2019

Aceito para publicação em: 26/12/2019 